\title{
Maltrato entre pares o acoso escolar (bullying). ¿Debemos enfrentar el problema cuando la tragedia es inevitable?
}

\author{
Abuse between peers or bullying. Should \\ we face the problem when tragedy is \\ inevitable?
}

Como consecuencia del lamentable evento acaecido a mediados del mes de enero de 2017 en la ciudad de Monterrey, Nuevo León, y el cual ha desencadenado una serie de opiniones gubernamentales, en los medios de comunicación electrónica y escrita, así como en algunos grupos de la sociedad civil de México, primordialmente surge la siguiente pregunta: ¿es que ante estos eventos, los mexicanos y, específicamente, los pediatras debemos reaccionar?

En general, todos los comentarios se refieren al hecho en sí; es decir, a las consecuencias de la agresión que sufrió una maestra y tres compañeros de clase, la cual fue realizada por un alumno y condiscípulo, con un arma de fuego.

Pocas personas que han opinado, mencionaron que probablemente el móvil de este joven haya sido la expresión final de un cuadro de maltrato entre pares o acoso escolar (bullying) y en el cual, probablemente, se encuentra insertado una modalidad más o menos novedosa y que se conoce como cyber-bullying. Eventualmente, alguien señaló la importancia de prevenir esta problemática; sin embargo, lo que habitualmente predomina son la consecuencias a veces tan lamentables.

Desde hace casi dos décadas en la Clínica de Atención Integral al Niño Maltratado del instituto Nacional de Pediatría (CAINM-INP) y posteriormente en la Coordinación Estudios Avanzados sobre Maltrato Infantil del mismo Instituto (CEAMI-P-INP) hemos hecho diversas referencias del problema: primero como un señalamiento del mismo al reiterar las diversas expresiones que puede tener esta patología en sus dos modalidades, la edad de los actores (agresor, agredido y compañeros observadores), las formas como ocurre en función a la edad de los menores, así como las consecuencias finales, entre las que destaca la agresión de un joven a sus compañeros, habitualmente, con arma de fuego, o bien, el suicidio del mismo.

¿Tienen que suceder eventos tan lamentables en nuestro país, como el ocurrido en Tamaulipas hace unos años, y en donde un escolar falleció como consecuencia de la agresión física de que fue víctima? En este caso, la respuesta del Gobierno Federal fue la creación de la Comisión 
Ejecutiva de Atención a Víctimas (CEAV) y ahora, lo de Monterrey, NL.

En CEAMI-P-INP hemos trabajado y presentado el libro: "Maltrato Infantil: gravedad y prevención", que cuenta con dos capítulos sobre el tema: "Maltrato entre pares o acoso escolar (bullying)" donde se presentan los aspectos clínico-sociales y legales del problema y otro: "Propuesta de un programa para la prevención del acoso escolar o maltrato entre pares". Este programa tiene como característica fundamental la inclusión de alumnos, padres de familia, profesores y autoridades escolares en un accionar transversal en lugar del tradicional programa vertical y en el que la indicación parte de la autoridad escolar (Dirección) hacia profesores, padres de familia y alumnos.

En cambio, estamos proponiendo este accionar transversal y en donde la llamada de atención o el señalamiento del problema parte de los alumnos hacia los padres; del menor y sus padres al profesor y de todos ellos, a la autoridad administrativa.

Los cambios de paradigma requeridos para cumplir con este programa son:

A. Modificación sustancial del programa educativo en padres, profesores y autoridades escolares destacando dos acciones fundamentales: "Escuchar al menor" y "Considerar el interés superior del niño."

B. Las niñas, niños y adolescentes deben tener la confianza de notificar a sus padres y a sus maestros la existencia de su problema con otros alumnos.

C. Los padres de familia deben escuchar a sus hijos, atender sus demandas y hablar con los profesores de la escuela. En caso necesario, también con las autoridades administrativas.
D. Los profesores deben escuchar a los alumnos y a los padres de familia para resolver los problemas que existieran respecto a la posibilidad de violencia entre pares o acoso escolar (bullying).

Para poder cumplir con este programa estamos proponiendo que al inicio de cada cursos escolar, se desarrolle una sesión informativa sobre lo que es el "Maltrato escolar entre pares o acoso escolar (bullying) en todos las escuelas y colegios gubernamentales o privados. Dicha sesión deberá estar dirigida por un profesional que conozca y entienda problemas tales como: dominar las características básicas del mismo, los factores desencadenantes, los actores involucrados y sus consecuencias a corto, mediano o largo plazo.

Esta sesión será de carácter obligatorio para padres de familia, profesores y autoridades escolares. Al final del curso escolar, los resultados deberán ser considerados y evaluados para su aplicación, en futuros años.

De una manera casi paralela, se propone el desarrollo de una sesión enfocada a conocer, recordar o enfatizar "los valores personales y familiares". Esta actividad deberá ser presentada y desarrollada por personal calificado, pero al margen de orientación política, religiosa o nivel socioeconómico.

Dos grandes problemas son de actualidad en la sociedad mexicana: la modificación de las familias y la existencia de violencia familiar. En el primer problema, destacan las familias monoparentales por:

A. Madres solteras

B. Madres separas/divorciadas

C. Madres que trabajan

Como consecuencia de ello, los niños asisten desde muy pequeños a guarderías gubernamen- 
tales o privadas y en donde son atendidos por personal que frecuentemente no está calificado. Las consecuencias de esta vivencia pueden ser diversos peligros tales como:

A. Ser víctimas de pederastia.

B. El personal solamente procura que el niño realice algunas actividades básicas como el comer, control de esfínteres, procurar un poco que hable o realice algunas actividades lúdicas.

En el segundo problema el menor es testigo de violencia familiar situación en donde frecuentemente también es víctima.

Las consecuencia de las dos condiciones puede ser:

A. La replicación de la violencia con sus compañeros (acoso escolar o maltrato entre pares [bullying]), que convierte al menor en victimario.

B. La inseguridad emocional o física del menor que lo transforma en víctima.

C. La falta de compromiso o solidaridad de sus compañeros por lo que se convierten en agresores activos o pasivos.

Finalmente, los pediatras debemos intervenir activamente en el diagnóstico temprano del problema, aunque lo más importante es prevenirlo, si es que hemos detectado factores de riesgo familiares, escolares o sociales. Recordar que nuestra misión es procurar la salud física y mental de este grupo etario y en donde destaca que la niña, el niño o el adolescente desarrollen su autoestima, autonomía, creatividad, felicidad, solidaridad y salud.

\section{Lecturas recomendadas}

1. Loredo Abdalá A. Maltrato entre pares o acoso escolar (bullying) En: Loredo Abdalá. Maltrato Infantil: gravedad y prevención. Editores de Textos Mexicanos. CDMX. 2017. pp. 71-91.

2. Loredo Abdalá A. Propuesta de un programa para la prevención del acoso escolar o maltrato entre pares. (bullying) En: Loredo Abdalá. Maltrato Infantil: gravedad y prevención. Editores de Textos Mexicanos. CDMX. 2017. pp. 93-118.

3. Gini G, Pozzoli T. Bullied children and Psychosomatic Problems: A Metaanalysis. Pediatrics. 2013;132:720-729.

4. Joffre Velásquez VH, García Maldonado G, Saldivar González AH. Martínez Perales G, Lin Ochoa D. Bullying in junior high-school students: general characteristics and associated risk factors. Bol Med Hosp Infant Mex 2011;68:177-185.

\section{Dr. Arturo Loredo-Abdalá}

Pediatra Internista. Especialista en el Estudio y Atención integral al Niño Maltratado e Investigador de la Coordinación de Estudios Avanzados sobre Maltrato Infantil-Prevención. Instituto Nacional de Pediatría ( CEAMI-P-INP) abycas_md@hotmail.com

Dra. Abigail Casas-Muñoz

Pediatra, M en C e Investigador de la Coordinación de Estudios Avanzados sobre Maltrato Infantil-Prevención. Instituto Nacional de Pediatría ( CEAMI-P-INP) abycas_md@hotmail.com 